\title{
Temperature and Light-Induced Changes in Bulk and Passivation Quality of Boron-Doped Float-Zone Silicon Coated With $\mathrm{SiN}_{\mathrm{X}}: \mathrm{H}$
}

\author{
David Sperber, Adrian Heilemann, Axel Herguth, and Giso Hahn
}

\begin{abstract}
In this study, it is observed that boron-doped floatzone silicon coated with hydrogenated silicon nitride shows strong instabilities in effective minority carrier lifetime after a fast firing step and subsequent treatment at elevated temperatures and illumination. During such a treatment, both degradation and recovery features are visible over time scales from minutes to months. To further investigate the observed behavior, corona charging series, capacitance voltage measurements, and chemical repassivation methods are applied. It is shown that a first fast degradation and recovery is associated with changes in the bulk lifetime, and it is observed that the fast firing step strongly influences this bulk instability. A subsequent slower degradation and recovery reflects changes in the effective surface recombination velocity that can be attributed to changes in the chemical passivation quality. It can be concluded that care has to be taken when boron-doped float-zone silicon is used as a supposedly stable high lifetime reference material after a fast firing step. Additionally, it can be stated that a silicon nitride related passivation may be far from stable at elevated temperatures and illumination after a fast firing step.
\end{abstract}

Index Terms-Charge carrier lifetime, crystalline silicon, degradation, float-zone (FZ), silicon nitride, silicon photovoltaics, stability, surface passivation.

\section{INTRODUCTION}

$\mathbf{S}$ ILICON grown by the float-zone (FZ) method is very impurity and oxygen lean and, therefore, often used as a reference material because of its supposed high bulk lifetime $\tau_{b}$, e.g., in solar cell process monitoring or to assess the quality of a surface passivation layer. It is known that the surface passivation quality can be subject to change under different treatment conditions [1]-[4] and even during storage at room temperature [5]. Often, the effective surface recombination velocity $\left(S_{\text {eff }}\right)$, the quantitative measure of passivation quality, is calculated with FZ samples under the assumption of $\tau_{b}$ being limited by Auger and radiative recombination only. However, depending on processing parameters, severe limitations in $\tau_{b}$ have been

The authors are with the Department of Physics, University of Konstanz, Konstanz 78457, Germany (e-mail: david.sperber@uni-konstanz.de; adrian.heilemann@uni-konstanz.de; axel.herguth@uni-konstanz.de; giso. hahn@uni-konstanz.de). observed in FZ silicon [6]-[11], making this assumption at least questionable.

Solar cell processing often includes a fast firing step in a belt furnace, which might change the lifetime stability of a sample. It could already be shown that boron-doped FZ samples show strong changes in effective minority carrier lifetime $\tau_{\text {eff }}$ when treated at elevated temperature and illumination after a fast firing step [12], [13]. Interestingly, single layers of hydrogenated silicon nitride $\left(\mathrm{SiN}_{\mathrm{x}}: \mathrm{H}\right)$ for surface passivation lead to a qualitatively similar long-term decline in $\tau_{\text {eff }}$ compared with layer stacks consisting of hydrogenated aluminum oxide $\left(\mathrm{AlO}_{\mathrm{x}}: \mathrm{H}\right)$ and $\mathrm{SiN}_{\mathrm{x}}: \mathrm{H}$ capping.

In this study, both changes in surface passivation quality and $\tau_{b}$ are investigated in fired samples coated with $\operatorname{SiN}_{\mathrm{x}}: \mathrm{H}$. To better understand the time dependence of possible short- and long-term degradation mechanisms, the samples are treated at different temperatures and illumination conditions. Therefore, the results are specifically interesting for the investigation of phenomena such as multicrystalline silicon (mc-Si) degradation [14]-[16] or boron-oxygen (BO) related degradation [17], where FZ samples are often used as reference samples to check for the stability of the surface passivation. However, the observed phenomena are not limited to degradation studies but reveal general traits of FZ silicon and $\mathrm{SiN}_{\mathrm{X}}: \mathrm{H}$ related surface passivation after a fast firing step.

\section{EXPERIMENTAL DETAILS}

\section{A. Sample Preparation}

As base material, boron-doped FZ wafers with a thickness of $250 \mu \mathrm{m}$ and specific resistivities $\rho$ of $1 \Omega \cdot \mathrm{cm}$ or $2 \Omega \cdot \mathrm{cm}$ were used. Some $1 \Omega \cdot \mathrm{cm}$ wafers were first etched to a thickness of $\sim 140 \mu \mathrm{m}$ using potassium hydroxide $(\mathrm{KOH})$ and afterward received a chemical polish in a solution of nitric acid, acetic acid, and hydrofluoric acid (HF). All samples then were cleaned in a solution of $\mathrm{H}_{2} \mathrm{O}_{2}$ and $\mathrm{H}_{2} \mathrm{SO}_{4}$ at $80{ }^{\circ} \mathrm{C}$ followed by a dip in HF (Piranha clean). Thereafter, the samples were coated with $\mathrm{SiN}_{\mathrm{X}}: \mathrm{H}$ on both sides using a direct plasma-enhanced chemical vapor deposition (PECVD) with a plasma frequency of $40 \mathrm{kHz}$ at a set temperature of $450{ }^{\circ} \mathrm{C}$. The resulting layers had a thickness of $\sim 70 \mathrm{~nm}$ and a refractive index of $\sim 2.0$ (at $600 \mathrm{~nm}$ ) as normally used in solar cell processing. Afterward, the samples were laser-cut into square samples of edge length $5 \mathrm{~cm}$. All samples then underwent a fast firing 
step in a belt furnace. The set peak temperature was adjusted so that all samples reached a measured peak temperature of $800{ }^{\circ} \mathrm{C} \pm 10^{\circ} \mathrm{C}$. The temperature measurement during the firing step was carried out using a thin type $\mathrm{K}$ thermocouple that was contacting the upper side of a sample by mechanical prestrain, thereby not significantly changing the sample properties. After the firing step, all samples were immediately stored in darkness at room temperature until a measurement series was carried out.

\section{B. Sample Treatment and Measurement Techniques}

The samples were treated on hotplates at temperatures ranging from 80 to $250{ }^{\circ} \mathrm{C}$. Illumination was achieved using halogen incandescent lamps with an illumination intensity of $\sim 1$ sun equivalent. Herein, 1 sun equivalent is defined as the intensity at which the amount of carriers generated within a sample equals that generated by solar illumination at $1.0 \mathrm{~kW} / \mathrm{m}^{2}$ using an AM1.5 spectrum.

For the repeated measurement of the effective minority carrier lifetime $\tau_{\text {eff }}$ during a treatment, a sample was temporarily removed from the hotplate and a photoconductance decay (PCD) measurement was carried out at $30{ }^{\circ} \mathrm{C}$ using a Sinton Instruments lifetime tester (WCT-120) [18]. All PCD measurements were evaluated at an injection level $\Delta n$ of one-tenth the doping density.

To assess changes in the $\mathrm{SiN}_{\mathrm{X}}: \mathrm{H}$ layer, corona charging (CC) series and capacitance-voltage $(\mathrm{CV})$ measurements were carried out. For the $\mathrm{CC}$ series, a setup comparable with the one described in [19] was used. During a CC measurement series, increasing amounts of negative charge are deposited onto a sample's surface (single sided) using a corona discharge at a voltage of $6 \mathrm{kV}$, and $\tau_{\text {eff }}$ is measured after each charging step. When $\tau_{\text {eff }}$ reaches a minimum, the least favorable ratio of minority and majority carriers is present at the surface, maximizing recombination via defect levels at the interface. Therefore, the remaining $\tau_{\text {eff }}$ is mostly a measure of the chemical passivation quality of a sample. After such a series, the charge is removed using deionized water.

During CV measurements, the rear side of a sample was lightly pressed on a circular metal electrode with diameter $2.5 \mathrm{~cm}$ leading to a metal-insulator-semiconductor (MIS) structure. On the front side, a dot-shaped MIS structure was created using a mercury probe. Because the diameter of the dot-shaped front side MIS structure was much smaller compared with the rear side, the voltage shift in a measurement signal mainly stems from the front side of a sample. This setup made the preparation of a conducting backside contact unnecessary and therefore allowed for repeated CV and PCD measurements during sample treatment. However, absolute values of measured capacitance differed significantly from one measurement to the other, probably due to differences in the distance between rear side and circular electrode. This made a normalization of the obtained measurement curves necessary.

Some samples had their $\mathrm{SiN}_{\mathrm{x}}: \mathrm{H}$ layer replaced with a wetchemical passivation after a treatment. The removal of the $\mathrm{SiN}_{\mathrm{X}}: \mathrm{H}$ layer was done by etching in concentrated HF. After-

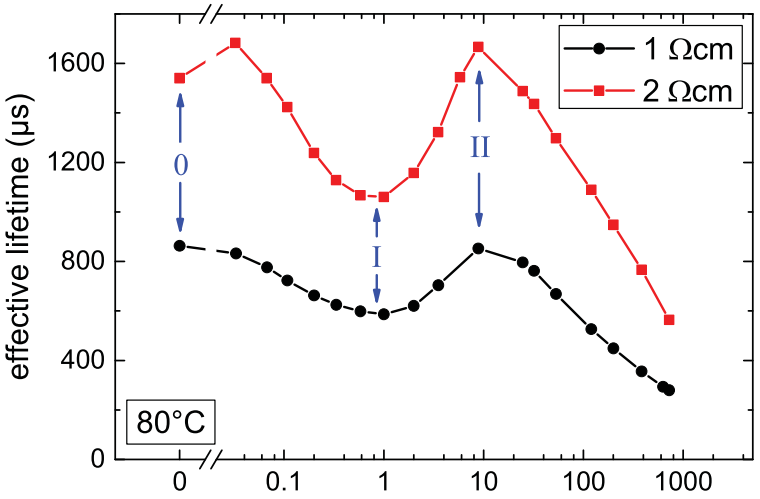

(a)

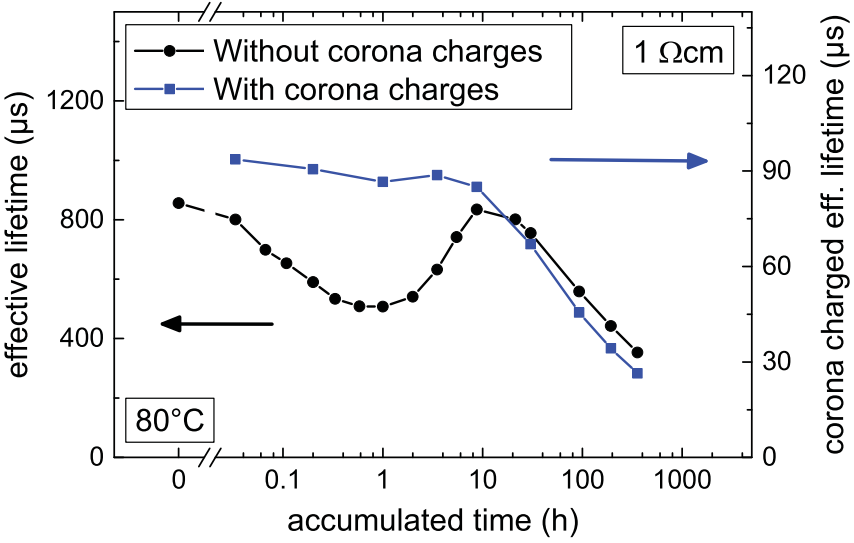

(b)

Fig. 1. (a) Two samples with different $\rho$ treated at $80^{\circ} \mathrm{C}$ and $\sim 1$ sun equivalent illumination intensity. (b) Another $1 \Omega \cdot \mathrm{cm}$ sample treated at $80{ }^{\circ} \mathrm{C}$ and $\sim 1$ sun equivalent illumination intensity (black, left axis). At selected points, the sample was corona charged into a minimum of $\tau_{\text {eff }}$ (blue, right axis). Lines only serve as a guide to the eye.

ward, the samples received a Piranha clean followed by an HF dip and were then wet-chemically passivated using a 0.08 molar iodine in ethanol solution [20]-[22]. The passivation quality of this solution is known to degrade significantly within minutes [22]. Therefore, $\tau_{\text {eff }}$ was always measured instantly after applying the wet-chemical passivation. Still, some variations in passivation quality of samples passivated with this procedure cannot be ruled out.

\section{RESULTS}

\section{A. Evolution of Effective Lifetime at Different Temperatures}

As can be seen in Fig. 1(a), already during a treatment at $80{ }^{\circ} \mathrm{C}$ and at 1 sun equivalent illumination intensity, significant changes in $\tau_{\text {eff }}$ occur both in a timeframe of minutes up to a timeframe of weeks. A difference between 1 and $2 \Omega \cdot \mathrm{cm}$ samples can only be found in the absolute values of $\tau_{\text {eff }}$. The temporal evolution, on the other hand, is very similar for both samples and will be denoted with roman numerals. Both show a minimum I in $\tau_{\text {eff }}$ after $\sim 1 \mathrm{~h}$ of accumulated treatment time, followed by a maximum II after $\sim 10 \mathrm{~h}$ followed by another decline in $\tau_{\text {eff }}$.

In Fig. 1(b), the temporal evolution of $\tau_{\text {eff }}$ of another $1 \Omega \cdot \mathrm{cm}$ sample treated at $80{ }^{\circ} \mathrm{C}$ and 1 sun equivalent illumination 


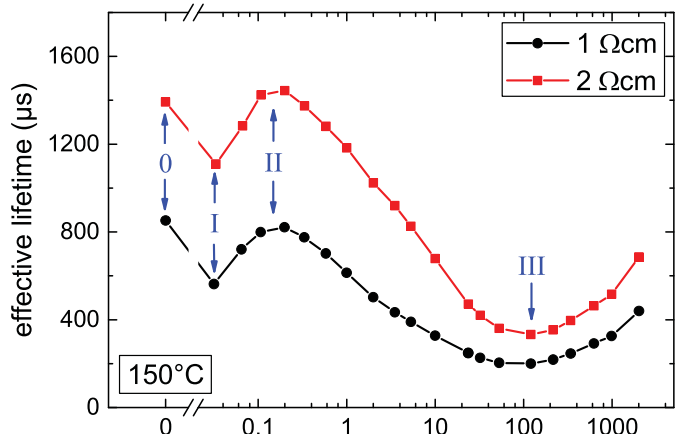

(a)

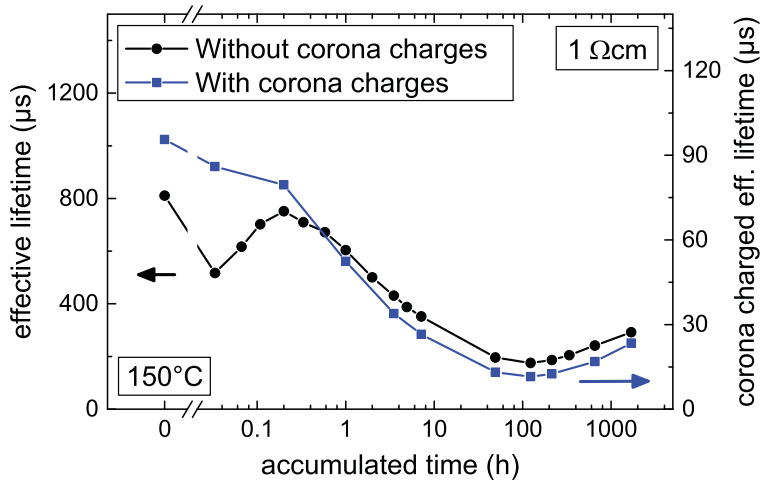

(b)

Fig. 2. (a) Two samples with different $\rho$ treated at $150{ }^{\circ} \mathrm{C}$ and $\sim 1$ sun equivalent illumination intensity. (b) Another $1 \Omega \cdot \mathrm{cm}$ sample treated at $150{ }^{\circ} \mathrm{C}$ and $\sim 1$ sun equivalent illumination intensity (black, left axis). At selected points, the sample was corona charged into a minimum of $\tau_{\text {eff }}$ (blue, right axis). Lines only serve as a guide to the eye.

intensity is shown. However, additionally, at specific points during the measurement series, CC series were performed. As can be seen, the $\tau_{\text {eff }}$ values of the sample without CC shown in black are very similar to the sample in Fig. 1(a); therefore, it can be concluded that the repeated CC procedure did not alter the sample properties significantly. The remaining and much lower $\tau_{\text {eff }}$ after CC (blue, right axis) is indicative for the chemical passivation quality of the sample. As can be seen, the first minimum I cannot be clearly identified in the corona charged state. This allows for two possible interpretations: Possibly, feature I is caused by a change in the fixed charge of the dielectric layer and, therefore, a change in the field-effect passivation. However, it is also possible that feature I is a bulk effect: In the corona charged state, the measured $\tau_{\text {eff }}$ is strongly limited by the surface recombination so that changes in the bulk are easily obscured. The origin of feature I will be discussed in more detail later on. The final decline in $\tau_{\text {eff }}$, however, can be seen in the corona charged state as well, which leads to the conclusion that this decline is correlated with a decline in chemical passivation quality.

As shown in Fig. 2(a), at $150^{\circ} \mathrm{C}$ and $\sim 1$ sun equivalent illumination intensity, once more the difference between the samples of different $\rho$ lies in the absolute values of $\tau_{\text {eff }}$ only, whereas the temporal evolution is similar for both samples. Again, a treatment combined with $\mathrm{CC}$ series gives insight into the mechanism at play and is shown in Fig. 2(b). As at $80^{\circ} \mathrm{C}$, at $150{ }^{\circ} \mathrm{C}$

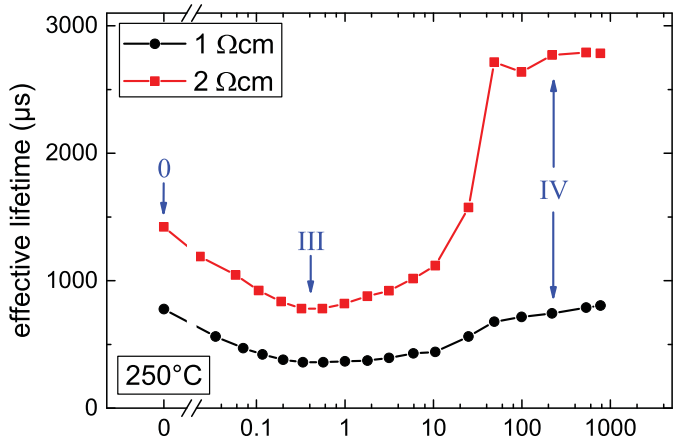

(a)

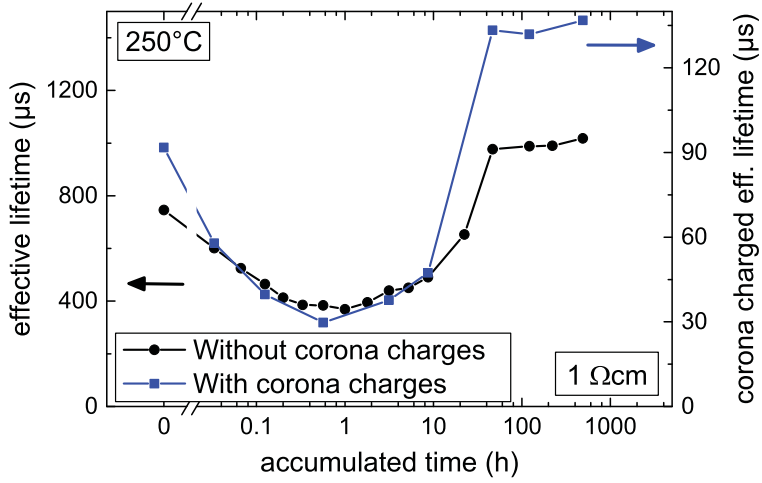

(b)

Fig. 3. (a) Two samples with different $\rho$ treated at $250{ }^{\circ} \mathrm{C}$ and $\sim 1$ sun equivalent illumination intensity. (b) Another $1 \Omega \cdot \mathrm{cm}$ sample treated at $250{ }^{\circ} \mathrm{C}$ and $\sim 1$ sun equivalent illumination intensity (black, left axis). At selected points, the sample was corona charged into a minimum of $\tau_{\text {eff }}$ (blue, right axis). Lines only serve as a guide to the eye.

treatment temperature also, the first dip in $\tau_{\text {eff }}$ is not associated with a significant change in chemical passivation quality of a sample and is, therefore, identified as feature I. The following decline after maximum II, however, is again visible as a significant drop in the corona charged $\tau_{\text {eff }}$. As a consequence, the minimum III after $\sim 100 \mathrm{~h}$ of treatment time is strongly associated with changes in chemical passivation quality. Interestingly, after reaching this minimum, $\tau_{\text {eff }}$ seems to recover both in the uncharged and charged state of the sample.

This trend is continued at $250{ }^{\circ} \mathrm{C}$ treatment temperature, where the minimum III is already reached after less than $1 \mathrm{~h}$ of sample treatment, and a strong recovery of $\tau_{\text {eff }}$ can be observed afterward in Fig. 3(a). The identification of feature III is again possible with CC series shown in Fig. 3(b). After $\sim 100 \mathrm{~h}$ of treatment time, $\tau_{\text {eff }}$ reaches a plateau IV both in the uncharged and the charged state of the sample.

A comparison of the injection dependence at different points of treatment is shown in Fig. 4. As can be seen, $\tau_{\text {eff }}$ decreases in all cases in high injection. This is at least in part caused by Auger and radiative recombination. Feature I also shows a rather low lifetime toward low injection, which is characteristic for a deep level defect according to the theory of Shockley, Read, and Hall [23], [24]. Concerning the other features, the injection dependence is rather flat at low injection. Feature III is additionally characterized by an overall strong limitation of $\tau_{\text {eff }}$. 


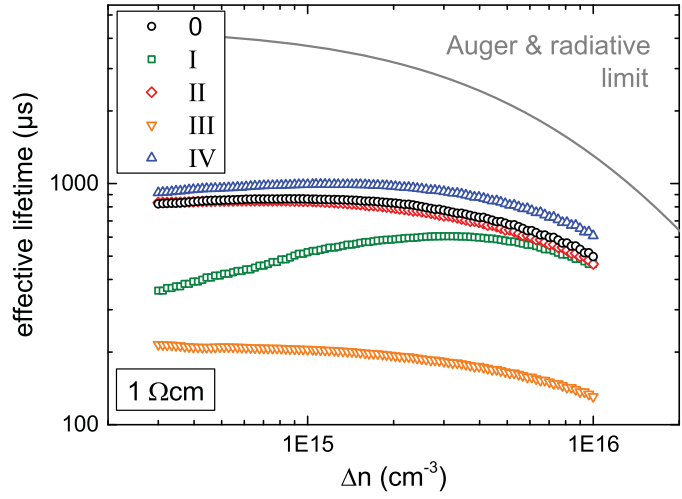

Fig. 4. Injection-dependent $\tau_{\text {eff }}$ at different points of treatment. Data for points 0 , I, II, and III were taken from the $1 \Omega \cdot \mathrm{cm}$ sample shown in Fig. 2(a). Data for point IV were taken from the $1 \Omega \cdot \mathrm{cm}$ sample shown in Fig. 3(b). Additionally, the bulk lifetime limit due to Auger and radiative recombination is shown according to the parameterization of Richter et al. [25].

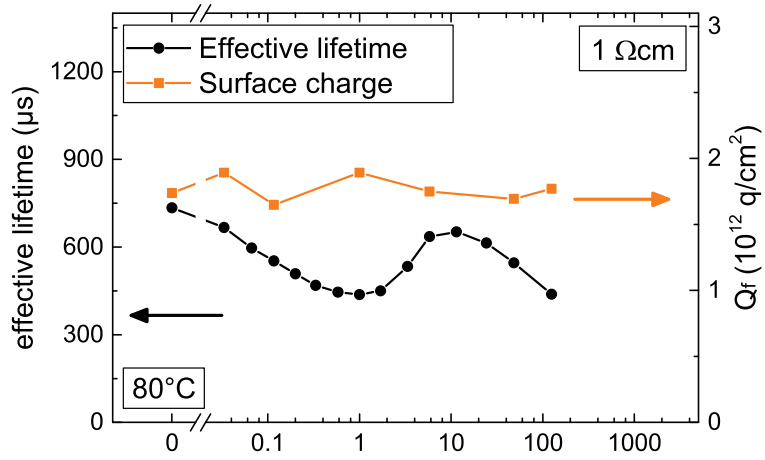

(a)

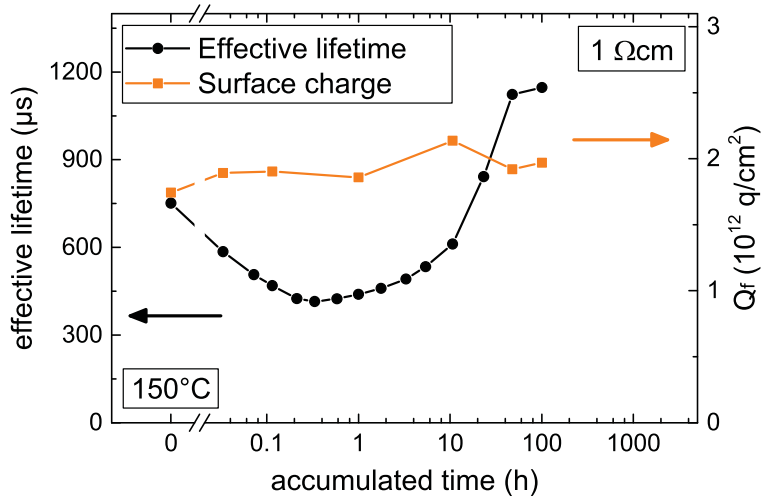

(b)

Fig. 5. Temporal evolution of $\tau_{\text {eff }}$ of (a) a $1 \Omega \cdot \mathrm{cm}$ sample treated at $80{ }^{\circ} \mathrm{C}$ and $\sim 1$ sun equivalent illumination intensity (black) and (b) another $1 \Omega \cdot \mathrm{cm}$ sample treated at $250{ }^{\circ} \mathrm{C}$ and $\sim 1$ sun equivalent illumination intensity (black). At selected points, $\mathrm{CV}$ measurements were carried out to measure $Q_{f}$ (orange), each on a new position of the sample surface. Lines only serve as a guide to the eye.

\section{B. Evolution of Fixed Charge}

Another two samples were treated at $80{ }^{\circ} \mathrm{C}$ and $250{ }^{\circ} \mathrm{C}$ and $\sim 1$ sun equivalent illumination intensity, respectively. Additionally, at some points during sample treatment, CV measurements were carried out, and the fixed charge density $Q_{f}$ was calculated. As can be seen in Fig. 5, there are only weak changes in the order of $10 \%$ around the mean value in the dielectric layer

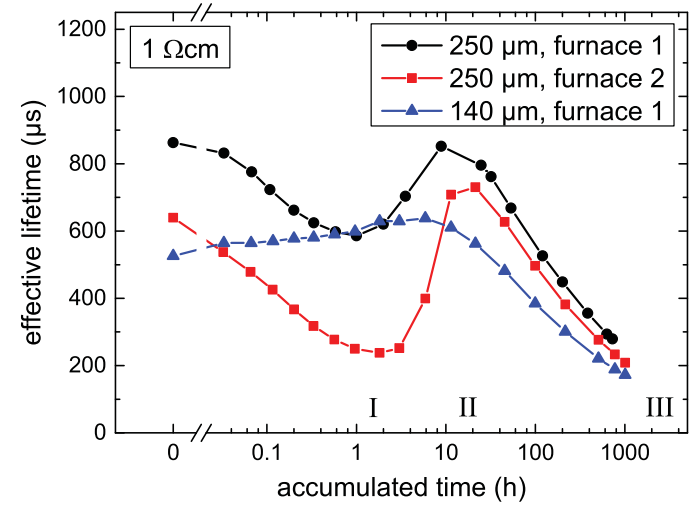

Fig. 6. Influence of variations in the fast firing step on sample evolution. All samples were processed using $1 \Omega \cdot \mathrm{cm}$ base material and treated at $80{ }^{\circ} \mathrm{C}$ and $\sim 1$ sun equivalent illumination intensity. The sample represented by circles (black) is the same as shown in Fig. 1(a). The sample represented by squares (red) is an identically processed sample that was fired in a different fast firing belt furnace. The sample represented by triangles (blue) was fired in the same belt furnace as the black one but was etched down to $140 \mu \mathrm{m}$ before sample processing. The set peak temperature was adjusted so that all samples reached a measured peak firing temperature of $\sim 800^{\circ} \mathrm{C}$ (see Fig. 7).

charge $Q_{f}$. Additionally, the observed changes do not seem to be correlated with the changes in $\tau_{\text {eff }}$.

Because every CV measurement was carried out on a new position of the sample surface, some variation in $Q_{f}$ is to be expected. However, a repeated measurement of an untreated sample at different points of the sample surface leads to a standard deviation of only $2.5 \%$. Therefore, the measured changes of up to $10 \%$ imply that the layer charge actually may change to some extent during the treatment.

A closer investigation of the $\mathrm{CC}$ series reveals that during the first $10 \%$ of total charging duration needed to minimize $\tau_{\text {eff }}$, the change in $\tau_{\text {eff }}$ is less than $10 \%$. In the beginning of the charging series, the charges are less repelled by already deposited charges. Therefore, at least $10 \%$ of the total charge should be deposited during these first $10 \%$ of total charging duration. This leads to the estimation that a $10 \%$ change in layer charge should not cause changes bigger than $10 \%$ in $\tau_{\text {eff }}$ of the samples shown here. Because the observed changes in $\tau_{\text {eff }}$ lie, however, in a range between $-40 \%$ at point I and $+50 \%$ at point IV relative to the initial value, it can be concluded that the observed change in layer charge and, therefore, a change in field-effect passivation is not the dominant cause of the changes in $\tau_{\text {eff }}$ observed in this study.

\section{Influence of Firing Step}

The fast firing step seems to be of crucial importance for a sample's evolution. It was already observed in [12] that the peak firing temperature exerts a strong effect on feature I, with a stronger decrease in $\tau_{\text {eff }}$ for higher measured peak firing temperatures. It was also noted that a sample that was annealed instead of fired did not show the instabilities observed here [13]. In Fig. 6, the effects of further variations in the firing step on feature I are shown. First, a sample was fired in a different fast firing belt furnace (furnace 2 ) leading to lower starting values and an 


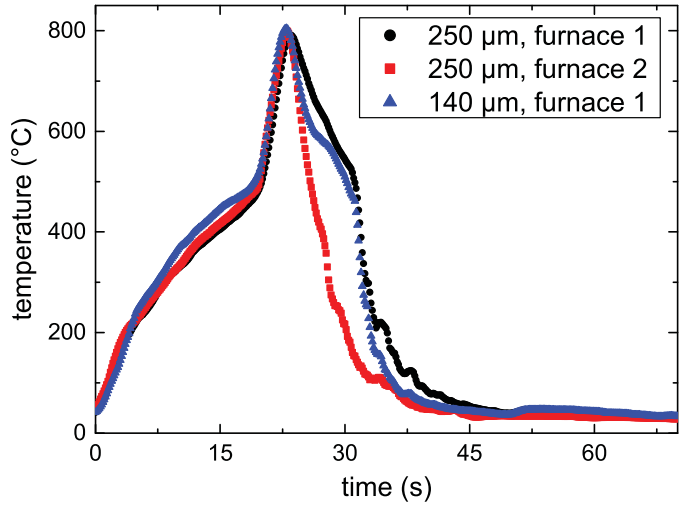

Fig. 7. Firing profiles of the three samples shown in Fig. 6. A time value of zero equals the point where a sample reaches $40{ }^{\circ} \mathrm{C}$. Slight oscillations in the measurement signal are due to vibrations of the type $\mathrm{K}$ thermocouple used for the temperature measurement and do not reflect real temperature oscillations of the sample.

even more pronounced minimum in $\tau_{\text {eff }}$ compared with a sample fired in the standard furnace (furnace 1). It has to be emphasized that in this case, the set peak temperature was adjusted so that the measured peak sample temperature was nearly the same for the firing processes in different furnaces. It is, therefore, assumed that other parameters of the firing step have a strong influence on the observed instability, as will be discussed below. This gets further backed up by the measurement of a thin sample shown in blue and also fired at an adapted set temperature in the standard furnace so that the measured sample temperature was similar to that of the thick samples. The starting value of $\tau_{\text {eff }}$ (blue) is a bit lower compared with the sample shown in black, which is to be expected due to a more dominant surface recombination in the thinner sample: Assuming a bulk lifetime limited only by Auger and radiative recombination according to the parameterization of Richter et al. [25] leads to an $S_{\text {eff }}$ value of $\sim 11 \mathrm{~cm} / \mathrm{s}$ for both samples and indicates that the difference in $\tau_{\text {eff }}$ arises mainly due to different thicknesses. Nevertheless, the thin sample shows a very different evolution with no significant instability (no minimum I) of $\tau_{\text {eff }}$ in the first hours of treatment. Although in this case $\tau_{\text {eff }}$ is more restricted by surface recombination, a similar bulk degradation as in the thick sample (black) should still cause a drop of $\tau_{\text {eff }}$ to $\sim 400 \mu$ s in the thin sample (blue) at point I, which is not observed. The data points of all samples finally converge when the degradation of the chemical passivation quality toward feature III sets in after $\sim 10-20 \mathrm{~h}$.

While it seems possible that the etching step of the thin sample prior to sample processing causes the observed differences, a sample etched to a thickness of $230 \mu \mathrm{m}$ shows a very similar behavior compared with the nonetched $250 \mu \mathrm{m}$ thick samples (data not shown). It is, therefore, strongly assumed that the observed differences are caused by the different firing conditions for samples of different thickness. One possible parameter explaining the different behavior of the samples could be the cooling rate after reaching the peak temperature. In fact, the two furnaces differ in their cooling rates, as can be seen in Fig. 7. However, the measured cooling rate of the thin sample lies in between those of the two thicker samples, and if the cooling

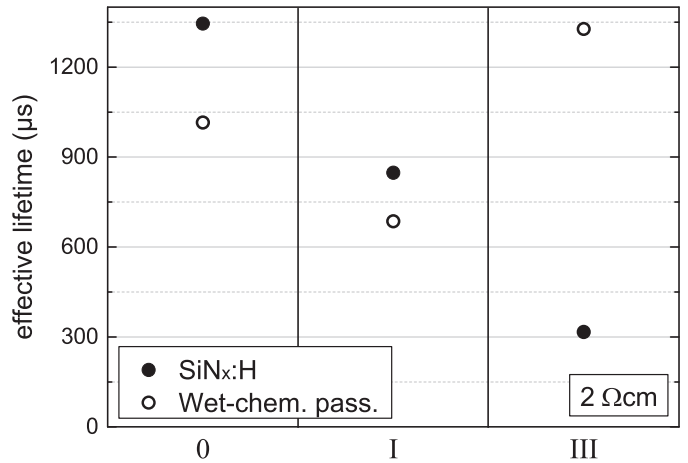

Fig. 8. $\tau_{\text {eff }}$ of different $2 \Omega \cdot \mathrm{cm}$ samples before and after applying a new wet-chemical passivation. Each column represents another identically processed sample at different points of treatment. Full symbols represent $\tau_{\text {eff }}$ with $\mathrm{SiN}_{\mathrm{x}}: \mathrm{H}$ and empty symbols show $\tau_{\text {eff }}$ after wet-chemical passivation with iodine/ethanol. All samples were processed in furnace 1. The drop in $\tau_{\text {eff }}$ in the untreated case shows the slightly inferior passivation quality of the wet-chemical passivation and also explains the slight drop at point I.

rate would be the dominant parameter, the thin sample would be expected to show a degradation behavior similar to the thick samples. Another important parameter of the firing step could be the set temperature that had to be adjusted to reach similar sample temperatures. A higher set temperature could lead to, e.g., stronger contamination by some substance found in the furnace.

\section{Changes After Wet-Chemical Repassivation}

It has been shown so far that feature I is neither caused by a change in chemical passivation quality nor in field-effect passivation. This leads to the assumption that feature I is not caused by changes in surface passivation quality but reflects changes in $\tau_{b}$. Therefore, replacing the passivating layer with a new wetchemical passivation at point I should not change the measured $\tau_{\text {eff }}$ significantly as long as $\mathrm{S}_{\text {eff }}$ of the wet-chemical passivation is comparable with that of the $\mathrm{SiN}_{\mathrm{x}}: \mathrm{H}$ layer. On the other hand, it was shown that feature III is probably caused by the changes in passivation quality. Therefore, replacing the $\mathrm{SiN}_{\mathrm{X}}: \mathrm{H}$ layer at point III should lead to a significant increase of $\tau_{\text {eff }}$.

To check for these assumptions, the $\mathrm{SiN}_{\mathrm{X}}$ :H layer was removed on selected samples at different points of sample evolution, and a new wet-chemical passivation using iodine/ethanol was applied. As can be seen in Fig. 8, the samples made out of $2 \Omega \cdot \mathrm{cm}$ material show the expected behavior: A sample at point I shows only minor changes in $\tau_{\text {eff }}$ with a wet-chemical passivation due to a slightly inferior passivation quality compared with $\mathrm{SiN}_{\mathrm{x}}: \mathrm{H}$, as can be seen from the untreated sample. In contrast, the change at point III is entirely different. The strongly increased $\tau_{\text {eff }}$ after repassivation proves that, in this case, the former interface properties have severely limited $\tau_{\text {eff }}$. This leads to the conclusion that feature I is in fact caused by changes in the FZ bulk, whereas feature III is caused by changes in surface passivation quality, which is in good agreement with the measurements shown before. The higher value of $\tau_{\text {eff }}$ after repassivation at point III compared with point I could indicate a $\tau_{b}$ exceeding its initial value after long-term treatment. It could, 
however, also be caused by a different level of surface passivation quality achieved with the iodine/ethanol solution.

Repassivation results of $1 \Omega \cdot \mathrm{cm}$ samples show the same qualitative behavior (data not shown). Interestingly, after repassivation, the decrease in $\tau_{\text {eff }}$ at point I is much more pronounced for a sample fired in furnace 2 compared with a sample processed in furnace 1. This is in good agreement with the data shown in Fig. 6 and shows that the differences between both furnaces, too, are caused by changes in the silicon bulk. To check whether the low $\tau_{b}$ at point I is caused by a thin subsurface layer (e.g., contaminated by in-diffusion or radiation damage), a $1 \Omega \cdot \mathrm{cm}$ sample at point I was repeatedly etched in $\mathrm{KOH}$ and passivated with iodine ethanol with the same procedure as before until a final thickness of $180 \mu \mathrm{m}$ was reached. During this procedure, $\tau_{\text {eff }}$ did not change significantly. This leads to the conclusion that the low $\tau_{b}$ at point I is not related to some kind of surface damage but to a defect that is rather uniformly distributed throughout the silicon bulk. Still, in- or out-diffusion of a substance related to feature I could occur faster in a thin sample during the fast firing step, possibly explaining the observed differences.

\section{Discussion}

To sum up what was observed so far, four characteristic features I, II, III, and IV have been identified during sample treatment at elevated temperatures and illumination. While a first minimum $\mathrm{I}$ is caused by a degradation of $\tau_{b}$ and followed by a recovery leading to a first maximum II, the second minimum III is related to changes in the chemical passivation quality of a sample, again followed by a recovery that leads to a plateau IV. It was shown that the temporal evolution is very similar for two different boron doping densities. Additionally, a similar behavior was observed when using a different furnace. In [12] and [13], it was already demonstrated that, again, a very similar behavior can be observed when using different PECVD systems and different chemical cleaning procedures. Therefore, the observed sample evolution seems to be a general behavior of samples with $\mathrm{SiN}_{\mathrm{x}}: \mathrm{H}$ related passivation after a fast firing step. Nevertheless, different FZ base materials should be compared in future investigations to draw final conclusions about the generality of the observed phenomena, especially regarding the degradation of $\tau_{b}$.

\section{A. Instability of FZ Bulk Lifetime}

At first glance, the observed bulk degradation feature I looks similar to the BO-related degradation. However, in this study, FZ silicon was used, which is usually not prone to BO degradation due to its low oxygen content. An upper limit of the oxygen content of the used FZ material of $10^{16} \mathrm{~cm}^{-3}$ as given by the material supplier should lead to a BO degraded lifetime of $\sim 40 \mathrm{~ms}$ in $1 \Omega \cdot \mathrm{cm}$ boron-doped material according to the parameterization of Bothe et al. [26] rendering BO degradation negligible with respect to the measured lifetimes. This parameterization was, however, determined using Czochralski-grown material with oxygen concentrations $>10^{17} \mathrm{~cm}^{-3}$ and a different thermal history.
In general, there are some similarities to other silicon bulk degradation phenomena: The processing conditions and especially a high temperature step seem to influence a sample so that it is either stable or degrades when subjected to an elevated temperature and illumination treatment, similar to BO degradation [27], [28] or mc-Si degradation [29]. The samples described here show both degradation and recovery at the same treatment conditions. This leads to the conclusion that the defect kinetics under investigation have to follow a three-state model similar to the one used in the description of the BO defect [30]-[32]: At the treatment conditions used in our study, the defect first switches from an initial state (as found after firing) to a degraded state leading to feature I. Afterward, there is a transition into a recovered state resulting in feature II. Further transitions, especially back into the initial or degraded state, do not seem to occur under the given treatment conditions. Transitions from point II back to point I or 0 at other treatment conditions, e.g., by annealing in darkness, seem to be possible and are discussed in a separate publication [33]. How far the mechanism of the observed recovery is related to mechanisms at play in other degradation phenomena such as $\mathrm{BO}$ or mc-Si degradation has to be further investigated.

The observed bulk instability could be related to [6] describing a defect in as-grown p-type FZ silicon. This defect was found to be activated both by a phosphorous gettering step at rather high temperatures and by a low-temperature illumination treatment and deactivated by a dark anneal at temperatures ranging from 250 to $650{ }^{\circ} \mathrm{C}$. However, while a sample in the cited study degrades again after an anneal at $400{ }^{\circ} \mathrm{C}$, one of our samples described in [13] did not show any degradation after annealing at $420{ }^{\circ} \mathrm{C}$. Therefore, a reason would have to be found to explain why our samples are able to reach a stable recovered state, whereas the samples in the cited study seem to only switch between the initial and degraded state. As an example, in BO studies, the difference between regenerating and nonregenerating samples is often suspected in different hydrogen content [27] and hydrogen bonding configuration in the silicon bulk [34], which is also a possible cause for differences between our samples and the samples in [6].

\section{B. Instability of Chemical Passivation Quality}

In addition to the FZ bulk lifetime instability, an instability of the chemical passivation quality was observed. This instability, too, seems to be related to the fast firing step because a sample shown in [13] that was treated directly after the $\operatorname{SiN}_{\mathrm{x}}: \mathrm{H}$ deposition shows a much weaker instability compared with a fired sample. Still, it is noteworthy that a qualitatively similar sample evolution can be seen also in a nonfired sample. Another sample that was not fired but annealed at $420{ }^{\circ} \mathrm{C}$ for $30 \mathrm{~min}$ does not show any instable behavior [13]. However, this sample could already have completed the temporal evolution during the annealing step and, therefore, be in state IV afterward.

So far, only a few parameters could be identified that change the severity of the observed surface passivation instability. It is assumed that the fixed layer charge has an influence because $\mathrm{AlO}_{\mathrm{x}}: \mathrm{H} / \mathrm{SiN}_{\mathrm{X}}: \mathrm{H}$ passivated samples show feature III much later 
compared with positively charged $\mathrm{SiN}_{\mathrm{x}}: \mathrm{H}$ passivated samples [12]. This is not the case for samples with positively charged $10 \mathrm{~nm} \mathrm{SiO}$ in place of the negatively charged $10 \mathrm{~nm} \mathrm{AlO}_{\mathrm{x}}: \mathrm{H}$ (data not shown). Therefore, it is assumed that the different sign of layer charge influences the interface properties in a way that slows down the instable behavior, possibly via changing the band structure close to the surface. Still, the instability could so far not be avoided but only delayed by using an intermediate layer of different charge.

Again, a sample degrades and recovers at the same treatment conditions, making a three-state model a promising approach for the description of the surface instability, even though it is not yet understood what causes degradation and recovery in particular. For both $\mathrm{SiO}_{\mathrm{x}}$ and $\mathrm{SiN}_{\mathrm{x}}: \mathrm{H}$ layers treated at temperatures of $500{ }^{\circ} \mathrm{C}$ and more, degradation and recovery features have been observed and were linked to a potential loss of hydrogen [35]-[37]. Additionally, it is known that the hydrogen bonding configuration may change during anneals at $250^{\circ} \mathrm{C}$ [38], which might cause changes in surface passivation quality as well.

As mentioned before, samples passivated with thermal $\mathrm{SiO}_{2}$ were found to suffer from a significant degradation of surface passivation quality during storage at room temperature [5]. Interestingly, our samples also show some degree of degradation when stored in darkness at room temperature (data not shown). Since this affects thin samples as well, it is assumed that this degradation is linked to a degradation of the surface passivation quality and potentially based on the same mechanism that was described here for samples treated at elevated temperatures.

\section{CONCLUSION}

Both a bulk lifetime and surface passivation instability have been identified in boron-doped FZ silicon samples that underwent a fast firing step and were subsequently treated at elevated temperatures and illumination. While the bulk degradation might be linked to a bulk defect that has only recently been discovered by Grant et al. [6] and is characteristic for p-type FZ silicon, the surface instability is caused by changes in chemical passivation quality. When using FZ reference samples in degradation or surface passivation studies, the observed effects should be taken into account.

It was shown that both degradation processes can be resolved by recovery processes that lead to a stable bulk and surface passivation quality under the given treatment conditions. Additionally, it was found that the observed bulk degradation can be avoided by using adapted sample thicknesses and, therefore, different set temperatures in the fast firing step. It can be speculated that the mechanism at play is also influencing $\mathrm{Cz}$ and $\mathrm{mc}-\mathrm{Si}$, where it could be easily obscured by other stronger degradation phenomena such as BO degradation or mc-Si degradation. Additionally, $\mathrm{Cz}$ and $\mathrm{mc}$ wafers used for photovoltaic applications are often thinner compared with FZ wafers so that lower set temperatures are used, thereby potentially reducing the impact of the discussed bulk degradation just like in thin FZ samples.

The defect kinetics observed here share some similarities with other degradation and recovery processes such as BO related degradation and mc-Si degradation, e.g., all of them share a strong dependence on the thermal history of a sample. In general, to search for common mechanisms shared by these similar degradation phenomena in different types of silicon appears to be an important and promising field for future research.

\section{ACKNOWLEDGMENT}

The authors would like to thank A. Graf, L. Mahlstaedt, B. Rettenmaier, J. Engelhardt, S. Joos, A. Zuschlag, and S. Fritz for technical support, Y. Schiele for assistance with CV data, and P. Keller for fruitful discussions. The content is the responsibility of the authors.

\section{REFERENCES}

[1] S. De Wolf, B. Demaurex, A. Descoeudres, and C. Ballif, "Very fast lightinduced degradation of a-Si:H/c-Si(100) interfaces," Phys. Rev. B, vol. 83, 2011, Art. no. 233301.

[2] J. Schmidt, M. Kerr, and A. Cueavas, "Surface passivation of silicon solar cells using plasma-enhanced chemical-vapour-deposited SiN films and thin thermal $\mathrm{SiO}_{2}$ /plasma SiN stacks," Semicond. Sci. Technol., vol. 16, pp. 164-170, 2001.

[3] S. Joos et al., "Light induced curing (LIC) of passivation layers deposited on native silicon oxide," Eng. Procedia, vol. 27, pp. 349-354, 2012.

[4] B. Veith, F. Werner, D. Zielke, R. Brendel, and J. Schmidt, "Comparison of the thermal stability of single $\mathrm{Al}_{2} \mathrm{O}_{3}$ layers and $\mathrm{Al}_{2} \mathrm{O}_{3} / \mathrm{SiN}_{\mathrm{X}}$ stacks for the surface passivation of silicon," Eng. Procedia, vol. 8, pp. 307-312, 2011.

[5] A. F. Thomson and K. R. McIntosh, "Degradation of oxide-passivated silicon," in Proc. 24th Eur. Photovolt. Sol. Energy Conf. Exhib., Hamburg, Germany, 2009, pp. 959-964.

[6] N. E. Grant, F. E. Rougieux, D. Macdonald, J. Bullock, and Y. Wan, "Grown-in defects limiting the bulk lifetime of p-type float-zone silicon wafers," J. Appl. Phys., vol. 117, 2015, Art. no. 55711.

[7] N. E. Grant et al., "Thermal activation and deactivation of grown-in defects limiting the lifetime of float-zone silicon," Phys. Status Solidi $R R L$, vol. 10, pp. 443-447, 2016.

[8] F. E. Rougieux, N. E. Grant, C. Barugkin, D. Macdonald, and J. D. Murphy, "Influence of annealing and bulk hydrogenation on lifetimelimiting defects in nitrogen-doped floating zone silicon," IEEE J. Photovolt., vol. 5, no. 2, pp. 495-498, Mar. 2015.

[9] N. E. Grant et al., "Permanent annihilation of thermally activated defects which limit the lifetime of float-zone silicon," Phys. Status Solidi A, vol. 213, pp. 2844-2849, 2016, doi: 10.1002/pssa.201600360.

[10] T. H. Wang, T. F. Ciszek, and T. Schuyler, "Charge carrier recombination centers in high-purity, dislocation-free, float-zoned silicon due to growthinduced microdefects," J. Cryst. Growth, vol. 109, pp. 155-161, 1991.

[11] G. D. Watkins, "Intrinsic defects in silicon," Mater. Sci. Semicond. Process., vol. 3, pp. 227-235, 2000.

[12] D. Sperber, A. Herguth, and G. Hahn, "Instability of dielectric surface passivation quality at elevated temperature and illumination," Eng. Procedia, vol. 92, pp. 211-217, 2016.

[13] D. Sperber, F. Furtwängler, A. Herguth, and G. Hahn, "On the stability of dielectric passivation layers under illumination and temperature treatment," in Proc. 32nd Eur. Photovolt. Sol. Energy Conf. Exhib, Munich, Germany, 2016, pp. 523-526.

[14] K. Ramspeck et al., "Light induced degradation of rear passivated mcSi solar cells," in Proc. 27th Eur. Photovolt. Sol. Energy Conf. Exhib., Frankfurt, Germany, 2012, pp. 861-865.

[15] F. Fertig, K. Krauß, and S. Rein, "Light-induced degradation of PECVD aluminium oxide passivated silicon solar cells," Phys. Status Solidi RRL, vol. 9, pp. 41-46, 2015.

[16] F. Kersten et al., "Degradation of multicrystalline silicon solar cells and modules after illumination at elevated temperature," Sol. Energy Mater. Sol. Cells, vol. 142, pp. 83-86, 2015.

[17] K. Bothe and J. Schmidt, "Electronically activated boron-oxygen-related recombination centers in crystalline silicon," J. Appl. Phys., vol. 99, 2006, Art. no. 13701

[18] R. A. Sinton and A. Cuevas, "Contactless determination of currentvoltage characteristics and minority-carrier lifetimes in semiconductors from quasi-steady-state photoconductance data," Appl. Phys. Lett., vol. 69, pp. 2510-2512, 1996. 
[19] S. W. Glunz, D. Biro, S. Rein, and W. Warta, "Field-effect passivation of the $\mathrm{SiO}_{2}-\mathrm{Si}$ interface," J. Appl. Phys., vol. 86, pp. 683-691, 1999.

[20] T. Horanyi, T. Pavelka, and P. Tüttö, "In situ bulk lifetime measurements on silicon with a chemically passivated surface," Appl. Surf. Sci., vol. 63, pp. 306-311, 1993.

[21] A. W. Stephens and M. A. Green, "Effectiveness of 0.08 molar iodine in ethanol solution as a means of chemical surface passivation for photoconductance decay measurements," Sol. Energy Mater. Sol. Cells, vol. 45, pp. 255-265, 1997.

[22] K. L. Pollock, J. Junge, and G. Hahn, "Detailed investigation of surface passivation methods for lifetime measurements on p-type silicon wafers," IEEE J. Photovolt., vol. 2, no. 1, pp. 1-6, Jan. 2012.

[23] W. Shockley and W. T. Read, Jr., "Statistics of the recombinations of holes and electrons," Phys. Rev., vol. 87, pp. 835-842, 1952.

[24] R. N. Hall, "Electron-hole recombination in germanium," Phys. Rev., vol. 87 , p. 387, 1952.

[25] A. Richter, S. W. Glunz, F. Werner, J. Schmidt, and A. Cuevas, "Improved quantitative description of Auger recombination in crystalline silicon," Phys. Rev. B, vol. 86, 2012, Art. no. 165202.

[26] K. Bothe, R. Sinton, and J. Schmidt, "Fundamental boron-oxygen-related carrier lifetime limit in mono-and multicrystalline silicon," Prog. Photovolt., vol. 13, pp. 287-296, 2005.

[27] S. Wilking, A. Herguth, and G. Hahn, "Influence of hydrogen on the regeneration of boron-oxygen related defects in crystalline silicon," J. Appl. Phys., vol. 113, 2013, Art. no. 194503.

[28] V. Voronkov and R. Falster, "The nature of boron-oxygen lifetimedegrading centres in silicon," Phys. Status Solidi C, vol. 13, pp. 712-717, 2016, doi: 10.1002/pssc.201600016.

[29] A. Zuschlag, D. Skorka, and G. Hahn, "Degradation and regeneration in mc-Si after different gettering steps," Prog. Photovolt., published online, doi: 10.1002/pip.2832

[30] A. Herguth, G. Schubert, M. Kaes, and G. Hahn, "A new approach to prevent the negative impact of the metastable defect in boron doped $\mathrm{Cz}$ silicon solar cells," in Proc. 3rd World Conf. Photovolt. Energy Conver., Waikoloa, HI, USA, 2006, pp. 940-943.

[31] A. Herguth, G. Schubert, M. Käs, and G. Hahn, "Investigations on the long time behavior of the metastable boron-oxygen complex in crystalline silicon," Prog. Photovolt., vol. 16, pp. 135-140, 2008.

[32] A. Herguth and G. Hahn, "Kinetics of the boron-oxygen related defect in theory and experiment," J. Appl. Phys., vol. 108, 2010, Art. no. 114509.

[33] D. Sperber, A. Herguth, and G. Hahn, "A 3-state defect model for light induced degradation in boron-doped float-zone silicon," Phys. Status Solidi $R R L$, published online, doi: 10.1002/pssr.201600408.

[34] S. Wilking, A. Herguth, and G. Hahn, "Influence of bound hydrogen states on BO-regeneration kinetics and consequences for high-speed regeneration processes," Sol. Energy Mater. Sol. Cells, vol. 131, pp. 2-8, 2014.

[35] T. C. Kho, K. R. McIntosh, J. T. Tan, A. F. Thomson, and F. W Chen, "Removal of hydrogen and deposition of surface charge during rapid thermal annealing," in Proc. 33rd IEEE Photovolt. Spec. Conf. Rec., San Diego, CA, USA, 2008, pp. 1-5.

[36] T. C. Kho, L. E. Black, and K. R. McIntosh, "Degradation of Si-SiO interfaces during rapid thermal annealing," in Proc. 24th Eur. Photovolt. Sol. Energy Conf. Exhib., Hamburg, Germany, 2009, pp. 1586-1590.

[37] F. W. Chen, J. E. Cotter, A. Cuevas, S. Winderbaum, and K. Roth, "Anomalous thermal behaviour of surface passivation by PECVD silicon nitride on p-type crystalline silicon," in Proc. 20th Eur. Photovolt. Sol. Energy Conf. Exhib., Barcelona, Spain, 2005, pp. 1419-1422.

[38] S. McQuaid, M. J. Binns, R. C. Newman, E. C. Lightowlers, and J. B. Clegg, "Solubility of hydrogen in silicon at $1300{ }^{\circ} \mathrm{C}$," Appl. Phys. Lett., vol. 62, pp. 1612-1614, 1993. 